The Journal of Laryngology \& Otology

http://journals.cambridge.org/JLO

Additional services for The Journal of Laryngology \& Otology:

Email alerts: $\underline{\text { Click here }}$

Subscriptions: $\underline{\text { Click here }}$

Commercial reprints: $\underline{\text { Click here }}$

Terms of use : $\underline{\text { Click here }}$

\title{
Prevalence of hyperventilation syndrome in an allergy clinic, compared with a routine ENT clinic
}

N Ogata, U Bapat, Y Darby and G Scadding

The Journal of Laryngology \& Otology / Volume 120 / Issue 11 / November 2006, pp 924 - 926

DOI: 10.1017/S0022215106001691, Published online: 02 June 2006

Link to this article: http://journals.cambridge.org/abstract_S0022215106001691

How to cite this article:

N Ogata, U Bapat, Y Darby and G Scadding (2006). Prevalence of hyperventilation syndrome in an allergy clinic, compared with a routine ENT clinic. The Journal of Laryngology \& Otology, 120, pp 924-926 doi:10.1017/S0022215106001691

Request Permissions : $\underline{\text { Click here }}$ 


\title{
Prevalence of hyperventilation syndrome in an allergy clinic, compared with a routine ENT clinic
}

\author{
N OGATA*†, U BAPAT*, Y DARBY*, G SCADDING*
}

\begin{abstract}
Objectives: A high prevalence of chronic hyperventilation syndrome in patients with asthma has been reported. We examined whether this phenomenon extended to allergy clinic patients in general and whether the prevalence was higher in patients attending a general allergy clinic compared with those attending a routine ENT clinic in our hospital.

Methods: We examined the prevalence of hyperventilation syndrome in unselected, consecutive patients $(n=100)$ seen in an allergy clinic. The validated Nijmegen questionnaire was completed by patients in the waiting room. We also administered the questionnaire to unselected, consecutive patients $(n=100)$ in a routine ENT clinic.

Results: There was no significant difference in prevalence of hyperventilation between allergy clinic and routine ENT clinic patients (25/100 vs 23/100).

Conclusion: The result indicates a high prevalence of hyperventilation amongst hospital attendees in general. Consideration should perhaps be given to the possible role of hyperventilation in symptomatology.
\end{abstract}

Key words: Hyperventilation; Hypersensitivity; Outpatients; Questionnaires; Otolaryngology

\section{Introduction}

A high prevalence of chronic hyperventilation syndrome in patients with asthma has been

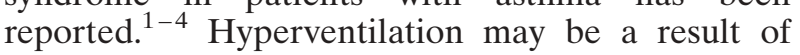
the increased anxiety found in some asthmatic patients, ${ }^{2}$ suggesting that there may be a high prevalence of hyperventilation in patients with other allergic diseases as well. Furthermore, understanding the existence of this condition in allergic patients might be beneficial when treating these patients. However, the prevalence of hyperventilation in general allergic patients has not been investigated.

In this paper, we examined whether the phenomenon of hyperventilation extends to allergy clinic patients in general, and we compared the findings from routine ENT clinic patients.

\section{Methods}

We audited consenting adults seen in the Royal National Throat, Nose and Ear Hospital. We examined the prevalence of hyperventilation syndrome in patients $(n=100)$ seen at our specialized allergy clinic, where we see patients suffering from food allergy, urticaria, angioedema and anaphylaxis, in addition to occasional rhinitis plus asthma.
The Nijmegen questionnaire ${ }^{5}$ was administered to a series of 100 consecutive patients chosen at random in the waiting room prior to the clinic visit. The questionnaire assessed 16 symptoms related to hyperventilation syndrome, on a five point scale (Table I). A total symptom score of $\geq 23$ has been reported as showing a sensitivity of 91 per cent and a specificity of 95 per cent as a screening instrument in patients with diagnosed hyperventilation syndrome. ${ }^{6}$

We compared these results with those from patients being seen in a routine adult ENT clinic $(n=100)$, in which allergic conditions were uncommon (as such patients were seen in a specialized clinic in our hospital).

Data about sex and the prevalence of a score $\geq 23$ within the two groups were compared using the $\chi^{2}$ test. We analysed the differences in age using Student's $t$-test.

\section{Results}

Results are shown in Table II. Of the allergic patients, 36 were male and 64 female, with an age range from 17 to 63 years (mean age (standard deviation (SD)), 39.7 (13.0) years). Twenty-five patients out of 100 scored $\geq 23$ on the Nijmegen questionnaire

From the * Royal National Throat, Nose and Ear Hospital, London, UK and the †Department of Otolaryngology - Head and Neck Surgery, Graduate School of Medicine, Kumamoto University, Kumamoto, Japan.

Accepted for publication: 5 January 2006. 
TABLE I

NIJMEGEN QUESTIONNAIRE

\begin{tabular}{|c|c|c|c|c|c|}
\hline Symptom & Never & Seldom & Sometimes & Often & Very often \\
\hline Chest pain & 0 & 1 & 2 & 3 & 4 \\
\hline Feeling tense & 0 & 1 & 2 & 3 & 4 \\
\hline Blurred vision & 0 & 1 & 2 & 3 & 4 \\
\hline Dizziness & 0 & 1 & 2 & 3 & 4 \\
\hline Confusion or loss of touch with reality & 0 & 1 & 2 & 3 & 4 \\
\hline Fast or deep breathing & 0 & 1 & 2 & 3 & 4 \\
\hline Shortness of breath & 0 & 1 & 2 & 3 & 4 \\
\hline Tightness across chest & 0 & 1 & 2 & 3 & 4 \\
\hline Bloated sensation in stomach & 0 & 1 & 2 & 3 & 4 \\
\hline Tingling in fingers and hands & 0 & 1 & 2 & 3 & 4 \\
\hline Difficulty in breathing or taking a deep breath & 0 & 1 & 2 & 3 & 4 \\
\hline Stiffness or cramps in fingers and hands & 0 & 1 & 2 & 3 & 4 \\
\hline Tightness around the mouth & 0 & 1 & 2 & 3 & 4 \\
\hline Cold hands or feet & 0 & 1 & 2 & 3 & 4 \\
\hline Palpitations in the chest & 0 & 1 & 2 & 3 & 4 \\
\hline Anxiety & 0 & 1 & 2 & 3 & 4 \\
\hline
\end{tabular}

(i.e. were Nijmegen questionnaire positive). The mean age (SD) was 42.9 (12.0) years for Nijmegen questionnaire positive patients, whilst that for Nijmegen questionnaire negative patients was 38.6 (13.2) years $(p=0.153)$. Although positive scorers were more likely to be female (male vs female: $6 / 36$ (16.7 per cent) vs 19/64 (29.7 per cent)), the difference was not significant $(p=0.229)$.

Of the ENT clinic patients, 51 were male and 49 female, the ratio of which did not differ significantly from that of allergy clinic patients. The age range of the ENT clinic patients was 12 to 77 years (mean age (SD), 46.0 (15.0)), which was significantly older than that of the allergy clinic patients $(p=0.002)$. Amongst these routine ENT clinic patients, there was no significant difference in age between Nijmegen questionnaire positive and negative patients (mean age (SD) of positive patients vs negative patients: 46.5 (11.1) years vs 45.9 (15.9) years; $p=0.853)$.

There was no significant difference in prevalence of hyperventilation between allergy clinic and routine ENT clinic patients $(25 / 100$ (25.0 per cent) vs 23/100 (23.0 per cent); $p=0.869)$.

\section{Discussion}

We used the Nijmegen questionnaire to examine the prevalence of chronic hyperventilation in patients seen in an allergy clinic compared with those seen in a routine ENT clinic. Our hypothesis was that the prevalence of hyperventilation syndrome in

TABLE II

PATIENTS WITH HYPERVENTILATION SYNDROME IN ALLERGY AND ENT CLINICS

\begin{tabular}{lccr}
\hline $\begin{array}{l}\text { Nijmegen } \\
\text { result }\end{array}$ & $\begin{array}{c}\text { Allergy clinic } \\
{[n(\mathrm{M}: \mathrm{F})]}\end{array}$ & $\begin{array}{c}\text { ENT clinic } \\
{[n(\mathrm{M}: \mathrm{F})]}\end{array}$ & $\begin{array}{c}\text { Total } \\
{[n(\mathrm{M}: \mathrm{F})]}\end{array}$ \\
\hline Positive & $25(6: 19)$ & $23(9: 14)$ & $48(15: 33)$ \\
Negative & $75(30: 45)$ & $77(42: 35)$ & $152(72: 80)$ \\
Total & $100(36: 64)$ & $100(51: 49)$ & $200(87: 113)$ \\
\hline
\end{tabular}

$\mathrm{M}=$ male $; \mathrm{F}=$ female patients in the allergy clinic would be comparable to that in asthma patients and would be higher than that in routine ENT clinic patients. The results were unexpected. Although the prevalence of hyperventilation syndrome in allergy clinic patients was comparable to that found in a previous report in asthmatic patients (in which about a third of women and a fifth of men (29 per cent of total patients) had positive scores), ${ }^{7}$ it was not significantly different from that found in ENT clinic patients.

There was no significant difference in age between Nijmegen questionnaire positive and negative patients in each group, unlike a previous study ${ }^{7}$ of asthmatic patients, in which Nijmegen questionnaire positive patients were significantly younger than negative patients. That tendency might be found only in asthmatic patients.

The lack of difference in prevalence of hyperventilation syndrome between the allergy group and the routine ENT group could represent a high prevalence of hyperventilation syndrome in out-patient clinics as a whole or could be related to the fact that patients in ENT clinics have upper respiratory tract problems which are known to affect the lower respiratory tract. ${ }^{8}$ The patients in the routine ENT clinic might tend to suffer from hyperventilation syndrome more than patients in other out-patient clinics. Further studies will clarify this.

As shown in a previous report, ${ }^{9}$ we must take into consideration the difficulty of diagnosing hyperventilation syndrome. We used the Nijmegen questionnaire, which has been shown by van Dixhoorn and Duivenvoorden to have a high sensitivity and specificity in a group of patients with hyperventilation. ${ }^{6}$ The questionnaire has been shown to be a useful assessment tool for hyperventilation because it is simple. We did not perform any other confirmatory tests to verify hyperventilation syndrome. Even if a provocation test is performed, there are some difficulties in diagnosing hyperventilation syndrome because such symptoms are not only due to hypocapnia. ${ }^{9}$

It is important to bear in mind when we see outpatients with allergy or ENT problems that the 
prevalence of hyperventilation syndrome is high and may be a cause of some of their symptoms, such as breathlessness, dizziness, nasal obstruction and the sensation of a lump in the throat. Consideration of this, and appropriate treatment, could be helpful in patients with otherwise unexplained symptoms.

- A high prevalence of chronic hyperventilation syndrome in patients with asthma has been reported

- This study examined whether this phenomenon extends to allergy clinic patients in general and whether the prevalence is higher in patients attending a general allergy clinic compared with those in a routine ENT clinic

- The prevalence of hyperventilation syndrome in unselected consecutive patients $(n=100)$ seen in an allergy clinic was examined using a validated Nijmegen questionnaire

- There was no significant difference in prevalence of hyperventilation between allergy clinic and routine ENT clinic patients (25/100 vs 23/100). There was a high prevalence of hyperventilation amongst hospital attendees in general, which merits further study

\section{References}

1 Carr RE. Panic disorder and asthma: causes, effects and research implications. J Psychsom Res 1998;44:43-52

2 Carr RE, Lehrer PM, Hochron SM, Jackson A. Effects of psychological stress on airways impedence in individuals with asthma and panic disorder. J Abnorm Psychol 1996; 105:137-41

3 Demeter S, Cordasco EM. Hyperventilation syndrome and asthma. Am J Med 1986;81:989-94

4 McClean AN, Howells J, Chaudri G, Boyd G. Use of the Nijmegen hyperventilation questionnaire and hyperventilation provocation test in a hospital asthma clinic. Am J Respir Crit Care Med 1999:159:A652

5 Van Doorn P, Folgering H, Colla P. Control of the end-tidal $\mathrm{pCO}_{2}$ in the hyperventilation syndrome: effects of biofeedback and breathing instructions compared. Bull Eur Physiopathol Respir 1982;18:829-36

6 Van Dixhoorn J, Duivenvoorden HJ. Efficacy of Nijmegen questionnaire in recognition of the hyperventilation syndrome. J Psychosom Res 1985;29:199-206

7 Thomas M, McKinley RK, Freeman E. Prevalence of dysfunctional breathing in patients treated for asthma in primary care: cross sectional survey. BMJ 2001;322: 1098-100

8 Scadding G. The coexistence of upper and lower respiratory airways diseases. Respir Dis Pract 1994;11:18-20

9 Hornsveld HK, Garssen B. Double-blind placebocontrolled study of the hyperventilation provocation test and the validity of the hyperventilation syndrome. Lancet 1996;348:154-8

Address for correspondence:

Dr Glenis K Scadding,

Royal National Throat, Nose and Ear Hospital,

Gray's Inn Road,

London WC1X 8DA, UK.

Fax: +44 2078335518

E-mail: g.scadding@ucl.ac.uk

Dr G Scadding takes responsibility for the integrity of the content of the paper.

Competing interests: None declared 